\title{
PENERAPAN FISHFINDER DAN PENGERING IKAN BAGI NELAYAN TANGKAP DI KELURAHAN MALABERO TELUK SEGARA KOTA BENGKULU
}

\section{IMPLEMENTATION OF FISHFINDER AND FISH DRYERS FOR FISHERMEN IN MALABERO TELUK SEGARA BENGKULU CITY}

\author{
Oleh: \\ Irkhos, M. Ginting, Nanang Sugianto \\ Jurusan Fisika, Fakultas MIPA, Universitas Bengkulu \\ Email: iazir@unib.ac.id
}

\begin{abstract}
Implementation of Fish-finder and Fish dryer for Fishermen in Malabero Teluk Segara Bengkulu City aims to apply appropriate technology. After all, this activity is expected to increase the efficiency and quality of dried fish as well as more catch and decreasing operational cost. Community service activity is implemented by training method. Through this activity we have produced the product of fish dryers and guidance of fish-finder use to determine fish position. Fish dryers amounted to 2 pieces of iron with each dimension of the same height $1.5 \mathrm{~m}$ long $1.8 \mathrm{~m}$ and width of $0.8 \mathrm{~m}$. One tool has 3 (three) drying racks with a total wide of $3.84 \mathrm{~m}^{2}$ with a tool capacity of approximately $20 \mathrm{~kg}$ of wet fish. The maximum temperature in the dryer room reaches $60^{\circ} \mathrm{C}$, and the time taken to dry the wet fish at a maximum temperature is about 8 hours.
\end{abstract}

Keywords: fish-finder, fish dryer, efficiency, quality

\section{PENDAHULUAN}

Jumlah rumah tangga usaha penangkapan ikan di Kecamatan Teluk Segara cukup banyak dan seluruhnya bekerja sebagai nelayan tangkap di laut. Sebagian besar dari mereka merupakan nelayan tradisional. Ikan tangkapan selain dijual langsung dalam bentuk ikan segar, juga dijual dalam bentuk kering yang telah diolah terlebih dahulu. Nelayan tradisional menggunakan perahu kecil berbahan bakar solar. Dalam sekali melaut, biaya operasional untuk bahan bakar mencapai Rp. 500,000 bahkan lebih. Hasil tangkapan dalam sekali melaut tidak menentu bergantung pada cuaca dan posisi ikan. Rata-rata ikan yang diperoleh dalam sekali melaut mencapai $300 \mathrm{~kg}$. Peralatan tangkap yang digunakan diantaranya jarring dan pancing (Bank Indonesia, 2013).

Pengolahan ikan kering cukup menjanjikan karena ketersedian bahan baku yang cukup serta menjadi lapangan kerja baru khususnya bagi ibu-ibu nelayan untuk menambah pendapatan rumah tangga. Sebagai sebuah usaha rumah tangga, pengolahan ikan kering menggunakan teknologi yang masih relatif rendah. Pengeringan ikan dilakukan oleh nelayan tradisional dengan cara menghamparkan di bawah sinar matahari dengan peralatan sederhana. Pada saat cuaca cerah pengeringan ikan membutuhkan waktu lebih kurang 1620 jam. Cuaca memberikan pengaruh yang sangat dominan dalam menjamin ketersedian ikan kering. Teknologi bagi usaha pengolahan ikan kering di Kota Bengkulu masih 
mengandalkan tenaga manusia dan belum pada rekayasa teknologi. Konsekuensinya adalah keseragaman mutu yang dihasilkan relatif sulit dicapai (Suci, 2007).

Posisi geografis Kota Bengkulu di pantai barat Sumatera dan menghadap ke Samudera Hindia memiliki potensi ekonomi tinggi disektor perikanan. Bengkulu memiliki potensi perairan laut mencapai 46,145 ton/tahunsedangkan potensi perairan laut zona ekonomi eksklusif (ZEE) mencapai 80,071 ton/tahun dan jumlah nelayan lebih kurang 3,756 orang. Produk ekspor Ikan segar hasil tangkap di perairan Kota Bengkulu seperti tuna, cakalang, bawal, kerapu, kakap, udang putih, udang windu, lobster, dan teripang. Sedangkan untuk konsumsi lokal dan regional, meliputi komoditi ikan tongkol, tenggiri, cucut, gurita, udang dogol, layur, cumi-cumi, dan lain-lain (Bank Indonesia, 2013). Sekitar $32 \%$ ikan tangkap di kota Bengkulu kurang bernilai ekonomis. Pemanfaatan ikan non ekonomis dengan rata-rata sebanyak $32 \%$ dari total produksi adalah sebagian kecil dikonsumsi segar dan sebagian besar lainnya diolah menjadi ikan kering atau dijadikan tepung ikan untuk berbagai kebutuhan pasar.

Fishfinder merupakan alat untuk melacak keberadaan ikan di laut, danau maupun sungai. Fishfinder dilengkapi dengan tranducer yang dipasang di bawah kapal, alat inilah yang akan mengirim sinyal ke dasar laut sehingga bisa dideteksi berapa kedalaman, keberadaan ikan, topografi bawah laut dan kita bisa melihatnya dari monitor yang dipasang di kapal (Ismail, 2010).

Fishfinder menggunakan prinsip kerja sonar (Sound, Navigation and Ranging). Sinyal suara yang dipancarkan oleh transmitter dipengaruhi oleh suhu air, kekentalan, serta kekeruhan air. Sinyal suara yang dipancarkan akan menjalar pada medium air. Ketika sinyal suara menjalar pada medium yang berbeda yaitu berupa objek yang ada di bawah permukaan laut maka sinyal tersebut dipantulkan kembali. Sebagian pantulan ditangkap oleh alat penerima atau receiver. Waktu tempuh sinyal suara tersebut dapat dikonversikan menjadi jarak atau kedalaman objek yang memantulkan sinyal suara tersebut.

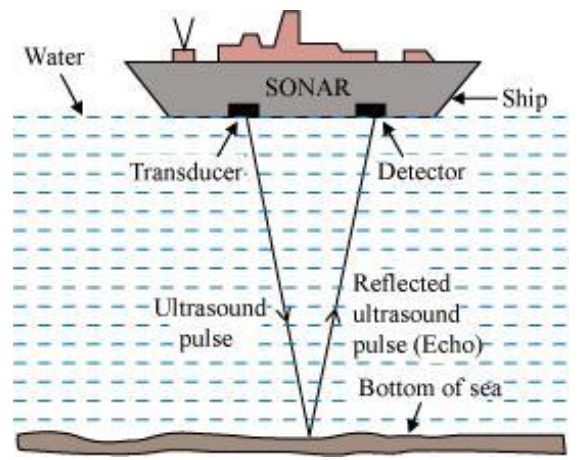

Gambar 1. Prinsip kerja SONAR dalam pengukuran kedalaman

Frekuensi sinyal yang dipancarkan oleh transmitter berpengaruh terhadap kinerja fishfinder. Semakin tinggi frekuensi sinyal yang dipancarkan maka semakin tahan terhadap gangguan eksternal namun penetrasi kedalaman semakin berkurang serta sudut jangkaun lebih kecil berkisar $15^{\circ}$ dan begitu pula sebaliknya untuk frekuensi yang lebih rendah dengan sudut jangkauan yang lebih besar berkisar $45^{\circ}$.

Kecepatan sinyal suara bergantung pada medium penjalarannya. Kecepatan suara di dalam air dapat dirumuskan dengan persamaan (1).

$$
v=f . \lambda
$$


Dengan v adalah kecepatan suara (m/detik), f adalah frekuensi sinyal suara $(\mathrm{Hz})$ dan $\lambda$ adalah panjang gelombang $(\mathrm{m})$.

Posisi Geografis Indonesia di wilayah khatulistiwa memiliki potensi energi surya melimpah sepanjang tahun. Energi surya dapat dimanfaatkan secara langsung sebagai sumber energi alternatif baik secara termal maupun non termal seperti energi listrik. Secara termal dapat dilakukan secara langsung tanpa peralatan tambahan maupun dengan menggunakan peralatan tambahan berupa pengumpul sinar dan pemfokus sinar matahari sehingga energi termal menjadi optimum.

Energi matahari dijalarkan ke permukaan dan diradiasikan ke dalam ruang angkasa. Dalam perjalarannya ke permukaan, 30\% energi matahari akan direfleksikan dan disebar kembali ke angkasa, memberikan bumi dan atmosfer albedo sekitar 30\%, sementara itu sebanyak $19 \%$ diabsorbsi oleh atmosfer dan awan serta $51 \%$ diabsorbsi oleh permukaan (Septiadi, 2009). Berdasarkan penelitian, energi yang dibebaskan oleh matahari setiap detiknya ekuivalen dengan konversi massa hidrogen yang besarnya adalah 4,2x10 ton/detik, yang ekuivalen dengan 1,2x10 KW (Zainul dan Erika, 2012). Di Indonesia melimpahnya cahaya matahari yang merata dan dapat ditangkap di seluruh kepulauan Indonesia hampir sepanjang tahun merupakan sumber energi listrik yang sangat potensial (Yuliananda dkk., 2015). Di dalam inti matahari terjadi reaksi termonuklir atau reaksi rantai proton-proton (reaksi p-p), yaitu pada empat proton terjadi fusi membentuk inti baru yang mengandung dua proton dan dua neutron. Dari reaksi ini dapat dihasilkan energi sebesar $25 \mathrm{MeV}$ atau 0,4 x 10-4 erg. Energi akibat kehilangan sejumlah massaakibat reaksi termonuklir dapat dinyatakan dengan:

$$
E=m \cdot C^{2}
$$

Dengan $C$ adalah cepat rambat cahaya dan $m$ adalah jumlah massa yang hilang. Dengan demikian kuantitas energi $(E)$, jumlahnya akan semakin besar, sehingga total energi yang dihasilkan dari tak berhingga reaksi fusi yang terjadi pada inti matahari dalam tiap detiknya akan sangat besar.

Pengeringan adalah proses pengeluaran kandungan air bahan hingga mencapai kandungan air tertentu agar kecepatan kerusakan bahan dapat diperlambat. Proses ini dipengaruhi oleh suhu, kelembaban udara lingkungan, kecepatan aliran udara pengering, kandungan air yang diinginkan, energi pengering, dan kapasitas pengering (Youce dkk., 2013).

Pengeringan ikan dapat ditinjau dari beberapa parameter yaitu perpindahan massa, kebutuhan energi pengeringan, Sistem perpindahan kalor secara konveksi, konduksi dan radiasi. Kebutuhan energi untuk mengeringkan dirumuskan pada persamaan 3.

$$
Q_{b}=\frac{M w}{t} x L_{H}
$$

Dengan $\mathrm{Qb}$ adalah panas yang dibutuhkan untuk mengeringkan bahan $(\mathrm{J} / \mathrm{s}), \mathrm{Mw}$ adalah massa air yang diuapkan dari bahan $(\mathrm{kg}), \mathrm{t}$ adalah waktu pengeringan (detik), $\mathrm{L}_{\mathrm{H}}$ adalah panas laten penguapan $(\mathrm{kJ} / \mathrm{kg})$. Perpindahan kalor yang terjadi pada alat pengering terjadi secara konduksi, konveksi dan radiasi. Perpindahan kalor secara radiasi terjadi dari sinar matahari ke alat pengering, secara konduksi terjadi pada plat kolektor alat pengering, kemudian kalor dari plat kolektor mengalami proses konveksi berupa massa udara panas bergerak naik dalam ruang alat pengering (Setyoko dkk., 2012). 


\section{METODE PENGABDIAN}

Solusi yang ditawarkan untuk menyelesaikan permasalahan mitra yaitu metode pelatihan penerapan fishfinder, rancang bangun alat pengering serta pendampingan manajemen usaha. Metode pendekatan yang ditawarkan untuk memecahkan masalah tersebut secara operasional adalah sebagai berikut:

\section{Tahap Persiapan}

Pada tahap persiapan dilakukan koordinasi tim dengan lembaga penelitian dan pengabdian kepada masyarakat (LPPM) dan khalayak sasaran pengabdian, pengurusan perizinan di Kelurahan Malabero Teluk Segara Kota Bengkulu, penyusunan rencana dan jadwal kegiatan serta dilakukan pembagian tugas kerja anggota tim.

\section{Pelaksanaan Kegiatan}

a. Sosialisai jadwal kegiatan dan materi kegiatan di lokasi pengabdian.

b. Pengumpulan alat dan bahan yang dibutuhkan di lokasi pengabdian yang terdiri dari pengadaan fishfinder portable c150, pengadaan bahan-bahan untuk membuat alat pengering seperti rangka baja tipis, plat fiber, plat besi tebal $3 \mathrm{~mm}$, atap fiber transparan, semen, koral, serta baut untuk rangka baja ringan.

c. Pendidikan dan pelatihan di lokasi pengabdian dilakukan untuk memberikan pengenalan berkaitan penggunaan alat penentu posisi ikan fishfinder, manfaat alat pengering ikan hybrid beserta materi dasar pembukuan yang baik dalam pengelolaan usaha kecil.

d. Pendampingan penggunaan fishfinder di lokasi pengabdian dilakukan secara langsung di lokasi nelayan biasanya menangkap ikan. Panduan penggunaan fishfinder yang mudah difahami disediakan bagi nelayan. Nelayan diupayakan dapat mengoperasikan sendiri fishfinder saat berangkat melaut.

e. Pembuatan alat pengering ikan hybrid tenaga surya-biomassa di lokasi pengabdian dengan bahan rangka baja ringan, dimensi bangunan alat pengering Tinggi dinding 3 $\mathrm{m}$, tinggi dinding + atap $4 \mathrm{~m}$, lebar bangunan $2 \mathrm{~m}$, dan panjang bangunan $4 \mathrm{~m}$. Rak sebanyak 6 tingkat dengan masing-masing tingkat memiliki luas lebih kurang $4,5 \mathrm{~m}^{2}$. Kolektor panas memiliki luas $8 \mathrm{~m}^{2}$. Suhu yang dihasilkan mencapai $58^{\circ} \mathrm{C}$ pada suhu lingkungan $30^{\circ} \mathrm{C}$. Alat dibuat bersama peserta kegiatan, selanjutnya nelayan dilatih cara menggunakan alat pengering ikan hybrid beserta cara pemeliharaan bangunan pengering ikan.

f. Setelah peserta dilatih menggunakan fishfinder, membuat alat pengering ikan, penggunaan serta pemeliharaan, tim akan melakukan pembimbingan dan pendampingan dalam pembentukan kelompok usaha kecil menggunakan manajemen yg lebih baik. Pelatihan manajemen usaha kecil di Universitas Bengkulu

\section{Cara Kerja Alat Pengering}

Alat pengering ikan yang diterapkan pada pengabdian merupakan alat pengering yang menggunakan radiasi energi sinar matahari dan biomassa (sekam dan atau kayu bakar) untuk meningkatkan suhu di dalam ruang pengering. Alat pengering memiliki dimensi: tinggi dinding $1,5 \mathrm{~m}$, lebar bangunan $0,8 \mathrm{~m}$, dan panjang bangunan $1,5 \mathrm{~m}$. Rak sebanyak 3 tingkat dengan masing-masing tingkat memiliki luas lebih kurang $1,5 \mathrm{~m}^{2}$. Kolektor panas yang terbuat dari plat besi tebal $3 \mathrm{~mm}$ berada pada bagia dasar alat pengering memiliki luas $1,5 \mathrm{~m}^{2}$. Kolektor suhu yang terdapat pada bagian bawah juga dapat dipanaskan dengan menggunakan sekam dan kayu bakar. Atap dan dinding terbuat dari fiber transparan. Alat pengering memiliki tiga rak bertingkat tempat meletakkan ikan 
yang akan dikeringkan. Sumber energi yang digunakan untuk meningkatkan suhu ruang pengering terdiri dari radiasi sinar matahari langsung pada ikan yang dikeringkan dalam ruang pengering serta kolektor suhu.

Ketika sinar matahari optimal (cuaca cerah) maka intensitas sinar matahari optimal meningkatkan suhu ruang secara radiasi. Namun ketika cuaca mendung sehingga intensitas sinar matahari tidak optimal diterima oleh alat pengering maka biomassa (sekam dana tau kayu bakar dibakar dibawah kolektor suhu agar suhu kolektor meningkat dan secara radiasi terjadi aliran panas ke dalam ruang pengering. Ikan yang dikeringkan terdiri dari berbagai jenis ikan dengan ukuran paling besar: tebal 0,01 m, panjang 0,1 $\mathrm{m}$ dan lebar 0,05 $\mathrm{m}$. Jumlah ikan yang dapat dikeringkan lebih kurang $10 \mathrm{~kg}$. Kapasitas alat pengering yang telah dibuat lebih kurang $10 \mathrm{~kg}$.

\section{Monitoring dan Evaluasi}

Untuk menjamin agar pelaksanaan kegiatan berjalan sesuai dengan rencana maka setiap tahapan kegiatan akan dilakukan monitoring. Persoalan pelaksanaan tiap tahapan segera diatasi agar tidak mengganggu tahapan kegiatan selanjutnya. Monitoring dan evaluasi juga dilakukan di masa akhir kegiatan agar tujuan kegiatan pengabdian benarbenar tercapai dan bermanfaat bagi semua pihak yang terlibat.

\section{HASIL DAN PEMBAHASAN}

Alat pengering ikan hybrid tenaga surya-biomassa pada kegiatan ini dibuat menggunakan bahan besi yang mudah didapat. Rencana awal kerangka dibuat menggunakan baja ringan, namun berdasarkan usulan dari peserta kegiatan dengan pertimbangan supaya alat pengering dapat dipindah-pindah maka kerangka haruslah lebih kokoh maka baja ringan diganti menjadi besi holo sebagai kerangka serta rak menggunakan bahan besi siku. Kerangka alat pengering dapat menggunakan bahan dari kayu maupun logam, sedangkan dinding dan atap dapat menggunakan plastik atau bahan fiber yang transparan. Plat kolektor (Solar Collector) menggunakan plat besi. Alat ini terdiri dari empat bagian utama yaitu:

1. Rangka bangunan.

2. Dinding dan Atap

3. Rak Ikan

4. Kolektor Surya

\section{Alat yang akan dibuat menggunakan bahan sebagai berikut:}

1. Rangka Bangunan berbahan besi holo

2. Dinding dan atap berbahan plat fiber transparan

3. Rak berbahan besi siku

4. Kolektor Surya berbahan plat besi dengan ketebalan 3-5 mm

\section{Dimensi dan Kapasitas Alat Pengering yang dibuat:}

Dimensi alat pengering: Alat pengering dibuat sebanyak 2 buah. Tinggi dinding 1,5 $\mathrm{m}$, lebar bangunan $0,8 \mathrm{~m}$, dan panjang bangunan 1,5 $\mathrm{m}$. Rak sebanyak 6 tingkat dengan masing-masing tingkat memiliki luas lebih kurang $1,5 \mathrm{~m}^{2}$. Kolektor panas memiliki luas $1,5 \mathrm{~m}^{2}$. Suhu yang dihasilkan mencapai $58^{\circ} \mathrm{C}$ pada suhu lingkungan $30^{\circ} \mathrm{C}$ (Gambar 4$)$. 


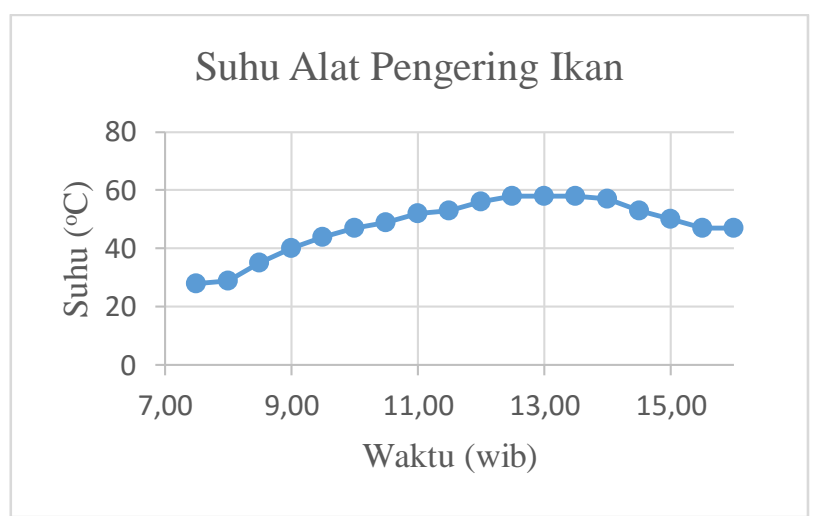

Gambar 4. Pengukuran suhu ruang alat pengering ikan hybrid surya-biomassa pukul 7.30 wib sampai dengan 16.00 wib pada kondisi cuaca cerah
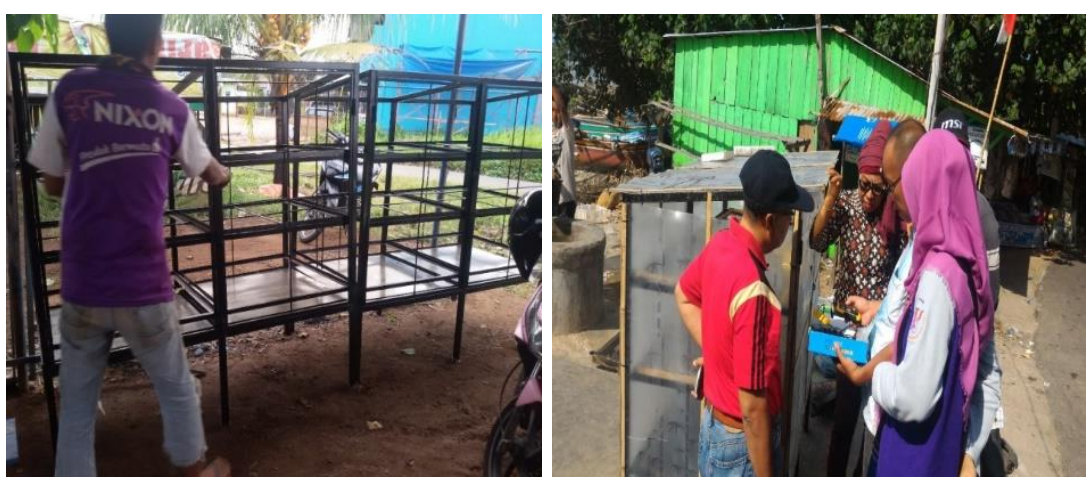

Gambar 5. a. Pembuatan kerangka alat pengering ikan, b. Alat pengering ikan yang siap digunakan

Kerangka alat pengering ikan menggunakan besi holo dan siku dibuat di bengkel las dengan lama pengerjaan lebih kurang enam hari. Kerangka yang sudah jadi kemudian dilanjutkan dengan pemasangan dinding serta atap menggunakan bahan plastic fiber transparan. Rak pengering dengan bingkai besi siku dilengkapi dengan jarring nilon sebagai alas meletakkan ikan basah yang akan dikeringkan (Gambar 5b)

Alat pengering ikan juga dilengkapi dengan pengukur suhu dan kelembaban. Alat ukur suhu dan kelembaban diposisikan untuk mengukur suhu dan kelembaban di dalam ruang alat pengering maupun di lingkungan. Berdasarkan hasil pengujian alat pengering, pada suhu lingkungan $30^{\circ} \mathrm{C}$ maka suhu di dalam ruang alat pengering mencapai $58^{\circ} \mathrm{C}$ dengan kelembaban $12 \%$. Kelembaban dapat diturunkan dengan membuka ventilasi alat pengering.

Alat pengering ikan dapat mempersingkat waktu pengeringan hingga setengan dari waktu pengeringan secara tradisional. Penggunaan alat pengering ikan ini dapat memberikan manfaat secara ekonomi dan kualitas ikan kering. Dari sisi ekonomi berdampak pada jumlah produksi ikan kering yang dapat dikeringkan untuk dijual, sedangkan dari sisi kualitas, ikan kering tidak tercemar oleh lingkungan sekitar.

\section{Alat Pelacak Posisi Ikan}

Fishfinder merupakan alat berbentuk monitor yang digunakan untuk mencari lokasi ikan. Fishfinderini terdiri dari transducer yang berfungsi sebagai sensor dan monitor yang berguna untuk menampilkan hasil gambar. Transducer ini terletak dibawah kapal, baik ditengah-tengah maupun dibelakang, dan berfungsi untuk mengirimkan sinyal-sinyal 
sensor ke bawah laut. Sinyal-sinyal tersebut akan memantul kembali setelah mencapai dasar dan kemudian sinyal tersebut akan kembali ditangkap oleh transducer untuk seterusnya di interpretasikan di monitor (Gambar 6.a).
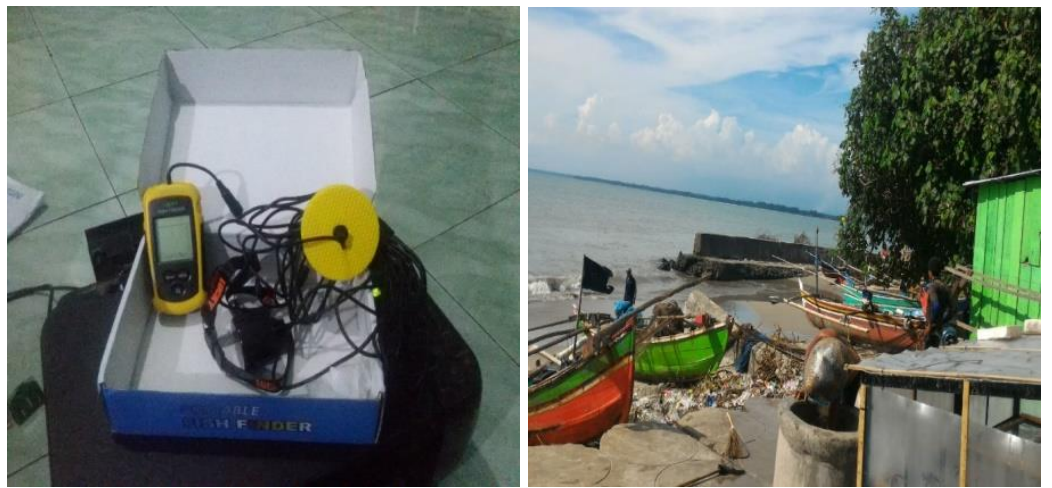

Gambar 6. a. Alat pelacak posisi ikan, b. Kapal nelayan tradisional yang akan menggunakan alat pelacak posisi ikan

Alat pelacak posisi ikan dapat digunakan oleh nelayan tradisional yang menggunakan kapal kecil. Sensor pelacak posisi ikan ditempatkan di bawah kapal menggunakan penyangga berupa logam atau kayu. Panjang kabel antara sensor dengan operator atau nelayan mencapai maksimal 10 meter. Hasil pengujian terkait tingkat akurasi pengukuran kedalaman menggunakan alat pelacak ikan yang digunakan untuk kegiatan PPM ini cukup tinggi mendekati $100 \%$.

\section{KESIMPULAN DAN SARAN}

\section{Kesimpulan}

Alat pengering ikan hybrid surya-biomassa dapat digunakan untuk mongeringkan ikan dengan durasi waktu yang lebih singkat yaitu lebih kurang 8 jam atau satu pertiga dari durasi waktu penjemuran secara tradisional dengan cara dihamparkan langsung. Suhu ruang pengering pada suhu lingkungan $30^{\circ} \mathrm{C}$ mencapai $58^{\circ} \mathrm{C}$ dengan kelembaban ruang lebih kurang $12 \%$. Kelembaban ruang pengering dapat diturunkan dengan cara membuka ventilasi udara alat pengering.

\section{Saran}

Pemanfaatan alat pengering ikan dan alat pelacak ikan dapat membantu menurunkan biaya pengeluaran operasional melaut serta meningkatkan efisiensi waktu serta kebersihan ikan kering olahan. Untuk memaksimalkan pemanfaatan teknologi di sarankan untuk meningkatkan kapasitas dan kuantitas alat pengering ikan untuk nelayan tradisonal khususnya di Kota Bengkulu.

\section{DAFTAR PUSTAKA}

Bank Indonesia, 2013, Pola Pembiayaan Umkm Usaha Pengolahan Ikan Kering Kota Bengkulu, Kantor Perwakilan Bank Indonesia Provinsi Bengkulu: Bengkulu.

Ismail, J.M, 2010, Identifikasi Material Dasar Perairan Menggunakan Perangkat Fishfinder Berdasarkan Nilai Target Strength, Skripsi Teknik Elektro, Universitas Indonesia: Depok. 
Septiadi, D, Nanlohy P, Francis Y, dan Rumlawang, 2009, Proyeksi Potensi Energi Surya Sebagai Energi Terbarukan (Studi Wilayah Ambon Dan Sekitarnya), Jurnal Meteorologi Dan Geofisika, 10(1).

Setyoko, B, Darmanto S, dan Rahmat, 2012, Peningkatan Kualitas Pengeringan Ikan Dengan Sistem Pray Drying, Prosiding SNST.

Suci, Putri Asriani, 2007, Kajian Sistem Agribisnis Perikanan Tangkap di Provinsi Bengkulu, Tugas Kuliah Ts Manajemen Agribisnis Program S3 Ekonomi Pertanian FP Universitas Gadjah Mada: Yogyakarta.

Youce, M. Bintang dkk., 2013, Konstruksi dan Kapasitas Alat Pengering Ikan Tenaga Surya Sistem Bongkar Pasang, Jurnal Media Teknologi Hasil Perikanan, 1(2).

Yuliananda, Gede Sarya, dan Ra. Retno Hastijanti, 2015, Pengaruh Perubahan Intensitas Matahari Terhadap Daya Keluaran Panel Surya, Jurnal Pengabdian Lppm Untag, $1(2)$.

Zainul, H, dan Erika R, 2012, Rancang Bangun Konversi Energi Surya Menjadi Energi Listrik dengan Model Elevated Solar Tower, Jurnal Neutrino, 4(2). 